\title{
Representação psíquica e teoria da linguagem nos textos iniciais freudianos: um estudo da monografia sobre as afasias ${ }^{1}$
}

\author{
Érico Bruno Viana Campos ${ }^{2}$ \\ Centro Universitário Hermínio Ometto de Araras, Araras-SP, Brasil
}

\begin{abstract}
Resumo: Este artigo aborda o tema da representação psíquica e sua vinculação com a linguagem na obra inicial de Freud. Apresenta os aspectos gerais da teoria da representação implícita no texto sobre as afasias e problematiza a leitura desses conceitos sob uma perspectiva contemporânea de linguagem. Defende que a teoria da representação, desde o início, está para além da estrutura da linguagem, pois essa abordagem é secundária à investigação do sentido das produções do inconsciente e das pulsões. Conclui que uma abordagem da representação sob o prisma da linguagem é um passo necessário, porém insuficiente, para o estudo da metapsicologia freudiana.
\end{abstract}

Palavras-chave: psicanálise, Freud, linguagem, representação mental.

\section{Psychic representation and language theory in Freud's initial work: a study of the monograph on aphasias}

\begin{abstract}
This article addresses psychic representation and its relation with language on Freud's initial studies. It presents an overview of Freudian theory of implicit representation in the monograph on aphasias and discusses the understanding of these concepts under a contemporary perspective of language. It defends that, since its beginning, the theory of psychic representation goes beyond the language structure because this is secondary to the investigation of the meaning of unconscious production and drives. The conclusion is that addressing the psychic representation under the perspective of language is necessary but insufficient for the study of the freudian metapsychology.
\end{abstract}

Keywords: psychoanalysis, Freud, language, mental representation.

\section{Representación psíquica y teoría del lenguaje en los primeros textos freudianos: un estudio de la monografía sobre las afasias}

\begin{abstract}
Resumen: Este artículo aborda el tema de la representación psíquica y su vinculación con el lenguaje desde el punto de vista de la metapsicología. Presenta los aspectos generales de la teoría de la representación implícita en la monografía de Freud sobre las afasias y problematiza la lectura de estos conceptos según una perspectiva contemporánea del lenguaje. Defiende que la teoría de la representación desde el inicio transciende la estructura del lenguaje, pues este abordaje es secundario en la investigación del sentido de las producciones del inconsciente y de las pulsiones. Se concluye que un abordaje de la representación según la perspectiva del lenguaje es un paso necesario pero insuficiente para el estudio de la metapsicología freudiana.
\end{abstract}

Palabras clave: psicoanálisis, Freud, lenguaje, representación mental.

O tema da representação psíquica está intimamente ligado a dois campos clássicos de investigação: o pensamento e a linguagem. A história das idéias já discorreu longamente sobre o assunto, fazendo desses dois campos aspectos ora complementares, ora equivalentes. Quer seja no âmbito da filosofia da linguagem (Auroux, 1996/1998), quer seja no âmbito das ciências da linguagem - no qual a linguística tem um papel de destaque - a questão foi abordada sob diversos prismas.

O propósito deste artigo é abordar essa questão, porém pelo recorte da metapsicologia freudiana e de sua teoria da

1 Apoio: CNPq. Este artigo é derivado da Dissertação de Mestrado defendida pelo autor junto ao Programa de Pós-graduação em Psicologia Experimental do Instituto de Psicologia da Universidade São Paulo, São Paulo, SP.

2 Endereço para correspondência:

Érico Bruno Viana Campos. Av. Dois Córregos, 1770. Casa 10. CEP 13.420-835. Piracicaba-SP, Brasil. E-mail: ericobvcampos@uol.com.br representação. Sem pretender ser exaustivo, procura discutir alguns aspectos gerais da articulação entre uma teoria da representação derivada da psicologia associacionista e uma abordagem sobre a linguagem. A questão central, portanto, é discutir a representação e a concepção de símbolo freudianas. Secundariamente, problematiza a leitura desses conceitos sob uma perspectiva das ciências da linguagem. Sabe-se que, contemporaneamente, após a interpretação lacaniana e a virada linguística na filosofia (Oliveira, 1996), essa aproximação é tomada como natural.

Apesar da noção de representação psíquica carregar consigo uma concepção sobre a linguagem e sua relação com o pensamento, ela não precisa, necessariamente, ser de caráter linguístico. É preciso, portanto, explicitar as concepções sobre a linguagem intrínsecas à teoria freudiana, ou seja, dela inferir uma filosofia da linguagem. Esse aspecto, contudo, não se encontra explicitado na obra de Freud, sendo um problema que percorre toda a metapsicologia, não equacionado devidamente. As razões disso são muitas, dentre elas a de 
que a preocupação freudiana não era propriamente teorizar sobre a linguagem, mas usar suas concepções para pensar o efeito do inconsciente na dinâmica psíquica, dentro da especificidade epistemológica da psicanálise.

Dentre os textos freudianos dos anos 1890, a monografia sobre as afasias (Freud, 1891/1977) é de particular interesse, pois é o único trabalho desse período que traz uma concepção explícita de teoria da representação. Muitos comentadores da obra freudiana têm retornado a ele texto com o intuito de discutir sua teoria da linguagem (Gabbi Jr., 1991; Garcia-Roza, 1998; Caropreso, 2003). Ali aparecem, pela primeira vez, os conceitos de representação de objeto e de palavra, que formam a base da concepção freudiana da memória e, posteriormente, serão integrados a uma teoria geral das pulsões. Além disso, nesse primeiro momento, esses conceitos ainda estão destituídos de uma concepção energética subjacente, sendo mais facilmente comparáveis ao campo da filosofia empirista e do associacionismo. Por último, o texto está voltado para os distúrbios da linguagem e não para o problema das neuroses. Esses aspectos possibilitam uma compreensão da ancoragem da teoria da representação psíquica em Freud, bem como a filosofia da linguagem intrínseca a ela.

\section{O símbolo em Freud}

A abordagem metapsicológica da representação está intimamente atrelada à idéia de símbolo. Nesse sentido há, já de partida, um problema, que é o de delimitar o conceito de símbolo em termos linguísticos, distinguindo-o do signo e de outras caracterizações linguísticas e semióticas. Tomarei em consideração, contudo, apenas a idéia de símbolo, que é o único termo aludido por Freud (Laplanche \& Pontalis, 1998; Arrivé, 1986/1994).

Constata-se facilmente o quanto esse termo é polissêmico e confuso. O Vocabulário da Psicanálise (Laplanche \& Pontalis, 1998) traz nada menos do que três caracterizações: (a) o simbólico, remetido ao conjunto de símbolos de significação constante que podem ser encontrados em diversas produções do inconsciente; (b) o simbolismo, no seu sentido geral de modo de representação indireta e figurada de uma idéia, conflito ou desejo inconscientes ou, ainda, no sentido específico de modo de representação que caracteriza pela constância na relação entre o símbolo e o simbolizado inconsciente, dentre os quais se destaca o simbolismo onírico; (c) o símbolo mnêmico ou mnésico, como forma de qualificação do sintoma histérico, na medida que simboliza um traço de memória que se encontra isolado da consciência.

Em todas essas definições, a idéia de símbolo está muito distante das acepções contemporâneas presentes nas ciências da linguagem ou mesmo da concepção de funcionamento simbólico do psiquismo, tal como compreendida pela psicologia.

Arrivé (1986/1994) efetua uma distinção semelhante sobre as concepções de símbolo em Freud: (a) símbolo mnêmico, (b) símbolo onírico e (c) símbolo como termo do processo de simbolização. O primeiro termo refere-se à inscrição corporal de um conflito que é símbolo de um traço mnêmico recalcado. Essa concepção de símbolo confundese com a noção de sintoma histérico, sendo resultado de uma simbolização inconsciente. Aproxima-se, assim, do terceiro termo, entendido de forma mais ampla como todo processo que une um conteúdo manifesto a um latente, sendo, contudo, mais evidente na formação de sintomas fóbicos. Nesse caso, em particular, não se trata de uma inscrição corporal, mas de um afeto, ou melhor, da expressão afetiva por conta de moções pulsionais recalcadas de caráter sobredeterminado. Tanto o primeiro quanto o terceiro termos, portanto, remetem à idéia de um deslocamento de significação consciente por conta de uma operação defensiva. Esse significado, uma vez deslocado, teria um correspondente simbólico - de natureza representacional, afetiva ou mesmo somática, no caso do sintoma histérico. O segundo termo, por sua vez, diz respeito apenas aos elementos simbólicos "universais" do sonho - não obstante sua polissemia e as ressalvas de Freud (1900/1996) contra o seu emprego desvinculado do conteúdo latente propriamente individual. Esse segundo caso isola-se dos outros dois por conta de um caráter restrito da motivação inconsciente, uma vez que o deslocamento da significação encontra-se apoiado em um sistema de símbolos universais.

Para a psicanálise, importa saber a gênese individual dos símbolos, os quais são entendidos como formações substitutivas motivadas por conflitos inconscientes. Evidentemente a concepção de simbolismo onírico traz algumas ressalvas, mas ela não se confunde com o símbolo descrito nas ciências da linguagem, já que se trata de uma concepção sobre o caráter universal de certas metáforas utilizadas no processo inconsciente de simbolização. Esse enfoque, por si só, já acarreta dificuldades para uma abordagem estritamente linguística do problema. Isso não apenas porque trata de símbolos motivados e individuais, mas, também, porque o deslocamento é pensado em termos energéticos e, em última instância, afetivos. O afeto é concebido por Freud (1894/1996) como uma intensidade energética que é retirada da associação com a idéia e pode ser tanto deslocada para outras representações ideativas ou se expressar de forma livre como descarga em direção ao somático, mecanismo que está na origem do afeto específico de angústia. Dessa forma, nessa concepção a angústia comparece como denominador comum da operação de defesa.

Essas considerações são suficientes para sustentar que a concepção freudiana de símbolo não aborda o problema do mesmo lugar que as concepções linguísticas. Sabemos que a concepção de signo da linguística pode ser definida como uma articulação arbitrária entre significado e significante cujo valor é dado pela estrutura da língua, sem precedência do significado ou do significante na gênese do signo ou interferência subjetiva na determinação do signo. A concepção freudiana de símbolo, por sua vez, encontra-se mais próxima do que poderíamos chamar de uma concepção psicológica. Como vimos, trata-se de uma formação substitutiva motivada por conflitos inconscientes, tendo, assim, uma gênese, 
uma sobredeterminação e um caráter sexual. Essa definição traz grandes dificuldades para a aproximação entre psicanálise e linguística, pelo menos da linguística estruturalista inaugurada por Saussure.

A princípio, as concepções linguísticas são marcadas pela arbitrariedade sígnica, estando em um pólo complementar à concepção motivada da psicanálise. O processo de simbolização - a gênese individual ou coletiva -, por sua vez, está fora de questão, uma vez que a linguística trataria da língua como sistema já estabelecido. No tocante à aptidão dos símbolos para significar o contrário e sua origem sexual há uma oposição absoluta: o tema não seria abordado pela linguística. Assim, entre psicanálise e linguística poderia haver apenas um questionamento mútuo (Arrivé, 1986/1994). Na verdade, o que se observa na teorização freudiana, em sua tentativa de elaborar a sobreposição inevitável entre a linguagem e as vicissitudes do inconsciente, é o artifício de fundamentar a linguagem sobre os mecanismos inconscientes.

\section{As hipóteses no estudo sobre as afasias}

A monografia sobre as afasias (Freud, 1891/1977) foi um texto deixado de fora das obras completas sob o argumento de se tratar de um texto estritamente médico. É bem verdade que se trata de um texto neuropsicológico, mas que se contrapõe à grande parte do establishment da época e lança propostas fecundas para uma concepção inicial de aparelho psíquico. Assim, acaba por transcender seu objetivo inicial, se revestindo de interesse para a compreensão das bases conceituais de uma das concepções centrais da metapsicologia freudiana: a representação psíquica. No que tange ao problema específico de que trata o presente artigo, a saber, a concepção de linguagem nas obras iniciais de Freud, esse texto é fundamental por ser o único momento em que é explicitada a concepção sobre a representação que está na base da teoria sobre os processos psíquicos.

O trabalho trata das afasias a partir da célebre discussão que marcou a neurologia do século XIX: a problemática localizacionismo x generalismo. A revisão da literatura procura mostrar as insuficiências da primeira hipótese como modelo heurístico e as vantagens de uma abordagem funcional, contrapondo Grashey e Jackson a Wernicke e Lichtheim. Essa discussão culminará na proposição de um modelo para a compreensão do aparelho psíquico em dois níveis: neurológico e psicológico. Apesar da abordagem necessária das concepções neurológicas freudianas, o interesse da presente discussão se dá no sentido de compreender sua concepção inicial acerca da representação psíquica.

\section{Nível neurológico}

As afasias são distúrbios da linguagem relacionados a algum grau de lesão ou disfunção do tecido cerebral responsável pelos diversos níveis de processamento da linguagem. Apresentam sintomatologias diferentes, a depender do tipo e localização do comprometimento neurológico. Sua classificação ainda hoje é controversa entre os especialistas, mas em geral distinguem-se algumas formas básicas, dentre as quais nos interessam particularmente: Broca ou motora - em que há dano na expressão -; Wernicke ou sensorial - em que há dano na compreensão -; e de condução - em que há dano na capacidade de reprodução (Auroux, 1996/1998, p. 233).

O cerne da concepção localizacionista é supor que há centros distintos na substância cinzenta, responsáveis pela articulação (área de Broca) e compreensão (área de Wernicke) da linguagem, os quais se ligam por vias de condução corticais. As terminações nervosas aferentes ou eferentes inserem-se nos centros e neles estão presentes as impressões sensoriais mais simples. Já as vias de condução em nada alteram as informações que carregam, ou seja, seriam territórios corticais com função meramente associativa. A interpretação das afasias seria dada da seguinte forma: lesões nos centros acarretariam em afasia motora ou sensorial, enquanto lesões nas vias associativas produziriam afasias de condução.

Essa noção está ancorada em uma abordagem anátomofisiológica compreendida como um associacionismo molecular que entende o corpo como representado ponto a ponto no córtex cerebral. Como aponta Gabbi Jr. (1991), a concepção de Wernicke parte de três postulados: (a) o aparelho da fala consiste de centros corticais distintos; (b) as células desses centros contêm representações; (c) os centros estão separados por território cortical sem função e ligados entre si por tratos associativos. Essa teoria sobre as afasias fundamentase, por sua vez, na teoria sobre o funcionamento do sistema nervoso de Meynert. Maiores detalhes sobre os fundamentos dessas teorias, bem como as hipóteses psicológicas nelas implícitas, são encontrados em Caropreso (2003).

A tônica da monografia é dada já por seu parágrafo inicial que argumentará em favor da hipótese funcional na consideração da parafasia (Freud, 1891/1977). Esse é o nome dado ao distúrbio em que há troca de palavras por outras relacionadas sintática ou foneticamente. Freud argumenta que essa sintomatologia não é necessariamente patológica, podendo ser igualmente encontrada em ocasiões de funcionalidade reduzida de uma consciência normal, como o sono, o cansaço ou sob a influência de intensidades afetivas. Ou seja, a patologia está relacionada a aspectos funcionais e não, necessariamente, a lesões anatomicamente identificáveis, o que implica certa reconsideração das relações entre normalidade e patologia. Essa perspectiva aproxima-se da noção de Grashey de uma reação solidária e global do tecido levando a uma perturbação funcional.

As patologias da linguagem não fariam mais do que repetir uma situação que se apresentaria normalmente durante a aprendizagem das funções de linguagem, com a diferença que viria ao auxílio do centro comprometido aquele que permanecesse mais eficiente, independente da hierarquia genética entre eles (Freud, 1891/1977). Para sustentar essa hipótese, Freud recorre à concepção de Hughlings Jackson sobre a involução funcional, a qual é compreendida como 
o modo de reação em que o tecido lesado retorna a estados anteriores de sua organização funcional, ou seja, formas de organização regressivamente mais simplificadas e menos associadas que expressariam também características funcionais menos especializadas e complexas (Freud, 1891/1977). A tônica da crítica está anunciada: contra o localizacionismo de Wernicke e Lichtheim, o funcionalismo de Grashey e Jackson.

O maior problema da hipótese localizacionista, tal como afirmada na época, se dava no embasamento de todo o seu argumento: a relação psiquismo $x$ fisiologia. Mesmo que esses autores houvessem considerado que apenas os elementos psíquicos mais simples - as impressões sensoriais - poderiam ser localizados na terminação do nervo periférico receptor do estímulo, o princípio continuava o mesmo: a modificação das fibras nervosas pela excitação produz outra modificação no corpo neuronal, que se tornaria o correspondente fisiológico da "representação". Dessa forma, a hipótese de um associacionismo molecular aplicado à anatomia cerebral implica uma concepção bastante peculiar da relação entre o somático e o psíquico. Haveria uma causalidade grosseira que explicaria a relação entre o impulso nervoso e a consciência através da impressão sensorial como imagem representada no centro nervoso: uma teoria anátomo-fisiológica do engrama mental, com uma vinculação direta entre o plano psíquico e o neurológico.

O mais grave, contudo, é que o localizacionismo se fundamenta em um argumento circular, pois inverte a relação explicativa ao tomar como metáfora para o nível fisiológico de abordagem o próprio nível psicológico que pretende explicar. Supõe, portanto, que haja uma localização pontual do correspondente fisiológico, tal como a psicologia discrimina representações elementares. Nessa censura, Freud encontra as posições de Jackson, que apontara o erro lógico de se afirmar a causalidade do físico no psíquico nos processos mentais. Propõe, então, uma relação de paralelismo para explicar a relação entre a fisiologia e os fenômenos mentais: "o psíquico é assim um processo paralelo ao fisiológico ('a dependent concomitant')" (Freud, 1891/1977, p. 56).

A idéia de um paralelismo psicofisiológico é fundamental para a compreensão da abordagem freudiana do problema mente-corpo, sendo na monografia sobre as afasias que o vemos enunciado pela primeira vez. Como bem mostrou Wino$\operatorname{grad}(2004 a, 2004 b)$, essa concepção freudiana sustenta uma posição que não se restringe a um monismo ou dualismo estritos, permanecendo até o final da obra de Freud.

A solução freudiana difere ao afirmar que a representação está assentada em um processo fisiológico, o qual é entendido como um investimento energético que modifica as vias corticais criando um registro de memória que se expressaria na forma de uma representação psíquica, denominada imagem mnêmica latente (Freud, 1891/1977). Essa concepção processual implicará, necessariamente, a dissolução da distinção entre sensação e associação, que o localizacionismo insistia em afirmar, de forma que a hipótese se assenta sobre a noção psicológica de que perceber é associar imediatamente. Assim, embora a dimensão processual não seja isomorfa nos níveis psicológico e fisiológico, ela deve ser compreendida por meio de um paralelismo. A conclusão é que a rejeição da distinção nas localizações das funções de representação e associação implica a rejeição da distinção entre centros e vias de condução da linguagem.

Não havendo uma distinção anátomo-fisiológica fundamental no córtex, mas sim um processo funcional integrado, é preciso estabelecer algum grau de estruturação ou hierarquização das funções. Freud propõe o processo de $s u$ perassociação, que ligaria em associações superiores grupos funcionais de associações. A dimensão processual associativa seria prejudicada nos processos patológicos, decorrendo daí a perda das funções secundárias antes das primárias em uma mesma região cortical (Freud, 1891/1977).

De forma a compreender melhor a organização desse campo cortical formado por vários níveis associativos, Freud (1891/1977) propõe um arranjo em que os centros formariam os ângulos do campo, ou seja, os pontos que delimitariam os vértices desse plano imaginário. Já a antiga região associativa da linguagem se encontraria entre os campos corticais dos nervos sensitivos e os respectivos centros corticais motores envolvidos na linguagem. Esses ângulos teriam função mais definida, devido às associações primárias, em contraposição aos campos mais internos, formados por associações secundárias. Decorreria daí a importância de lesões nessas extremidades, pois gerariam quadros afásicos mais definidos. Assim, as considerações a respeito da hierarquização das funções da linguagem no córtex fazem com que Freud proponha um esquema anatômico do campo associativo da linguagem (1891/1977), cujo propósito é ser um modelo heurístico para o diagnóstico diferencial das afasias no nível neurológico, com a derivação de sintomas sensitivos e motores associados.

O modelo anatômico é cunhado a partir da desmontagem ponto a ponto da hipótese localizacionista e dos seus pressupostos fisiológicos, apontando o erro lógico de se construir um modelo anatômico a partir de pressupostos psicológicos, tão comum à época. Segundo alguns comentadores, essa seria a mais importante contribuição da monografia (Caropreso, 2003). Essa afirmação só é justa se tomada no sentido da contribuição da monografia para a querela neurológica da época. Para os propósitos deste artigo, interessa a solução que Freud opera ao problema mente-corpo, em termos de um paralelismo fisiológico e as derivações que fará em direção ao nível psicológico da linguagem.

Não há constrangimento algum por parte de Freud (1891/1977) em desenvolver dois modelos em níveis de abordagem diferenciados, sem tentar efetivamente relacioná-los entre si. O paralelismo anunciado como resposta ao problema da relação entre o neurológico e o psicológico é desenvolvido nas duas direções sem que se trate mais especificamente da integração entre eles. Freud (1891/1977) silencia quanto ao estatuto do dependent concomitant, deixando a 
impressão de um paralelismo psicofisiológico, o qual tem a importante função de descartar o epifenomenismo como modelo explicativo - já que o nível psicológico da problemática é igualmente abordado.

Freud demorará ainda um bom tempo para elucidar a questão à sua própria maneira, por meio do conceito de pulsão, no qual a relação entre somático e psíquico passa a ser entendida de outra forma. Cabe ressaltar, contudo, como, neste momento do percurso freudiano, essa problemática é anunciada. A partir dos dois modelos apresentados, surgem duas possibilidades de abordagem do aparelho psíquico: uma neurológica e outra psicológica. O interessante é que os dois grandes trabalhos metapsicológicos subseqüentes procuram explorar essas duas possibilidades: o Projeto de uma Psicologia (Freud, 1895/1995), pela vertente neurológica, e o sétimo capítulo de A Interpretação de Sonhos (Freud, 1900/1996), pela vertente psicológica.

Freud (1891/1977) retira algumas conclusões importantes para a consideração psicológica das relações anatômicas e funcionais estabelecidas no nível neurológico. Observa que o elo mais fraco da atividade de linguagem se daria na ligação entre os componentes de objeto e os de palavra, já que seria esta a dimensão mais superassociada do processo. O próprio conceito de superassociação vem responder à necessidade de estruturação funcional da região cortical da linguagem a partir de um duplo legado: a concepção jacksoniana de involução funcional e a filosofia associacionista. Cabe, portanto, explicitar as particularidades da concepção freudiana de associacionismo, o que será feito a partir da apresentação do esquema psicológico.

\section{Nível psicológico}

As considerações neurológicas e seus pressupostos teóricos fornecem os elementos para conceber as relações associativas da linguagem em outro nível de abordagem, superposto ao campo cortical: o esquema psicológico da representação de palavra (Freud, 1891/1977). Esse modelo psicológico para a linguagem consiste em um campo associativo de representações de dois tipos: (a) a representação de objeto, um complexo associativo aberto formado pela superassociação de imagens táteis, acústicas, visuais, entre outras; (b) a representação de palavra, um complexo associativo fechado formado pela superassociação da imagem acústica, motora, da escrita e da leitura. A ligação entre as duas representações se dá entre a imagem acústica da palavra e a imagem visual do objeto.

Freud (1891/1977) deriva desse modelo uma classificação das afasias. Há níveis de associação entre os diversos componentes do campo de linguagem entre si. Da mesma forma, entende-se que essas associações procuram representar no plano subjetivo um objeto externo inacessível de forma imediata, o que faz com que seja compreendido como coisa em si ou referente. A dissolução das associações da representação de palavra estaria em jogo nos quadros de afasia verbal. Como essa perturbação ocorre dentro de um campo de associações primárias é considerada uma afasia de primeira ordem. Já a perturbação da associação entre a representação de objeto e a de palavra está em jogo na afasia simbólica. Nesse caso, a dissolução associativa se dá entre dois complexos associativos, daí a denominação de afasia de segunda ordem.

Outra perturbação de segunda ordem é aquela que envolve a relação de correspondência entre o objeto e a representação de objeto. Essa relação, contudo, se dá fora do campo associativo da linguagem, não sendo propriamente uma afasia. Esse tipo de distúrbio é denominado agnosia, em que não há um reconhecimento perceptivo do objeto. Isso não impede, contudo, que lesões dessa natureza influenciem a competência linguística dos sujeitos. Pode ocorrer que o sujeito reconheça o objeto, mas não possa nomeá-lo. Nesse caso, tem-se a afasia agnósica. Esta constitui uma afasia de terceira ordem, pois a relação associativa em jogo envolve a perda da intermediação do complexo representativo de objeto. Não é meu interesse pensar a aplicabilidade dessa classificação na compreensão das afasias. Ela é apresentada na medida que organiza as relações entre os três termos que, classicamente, são enumerados nos estudos sobre a linguagem como tríade semiótica - o objeto externo, o conceito e a palavra -, ajudando a discutir alguns pontos da concepção freudiana sobre a linguagem. Seu interesse se dá porque é nesse ponto, no qual é introduzido o esquema psicológico da representação de palavra, que se encontra a única formulação explícita de uma concepção sobre a natureza da linguagem em Freud.

Deve-se compreender o modo de constituição dessas representações e que tipo de relação se estabelece entre elas, bem como em relação ao objeto externo. Trata-se de entender como o objeto é representado na consciência e qual a relação da linguagem com esse ato de consciência. Em suma, a questão concerne à relação que se observa entre pensamento e linguagem, além da própria filosofia da linguagem que funda essa relação.

Como foi visto, a concepção de representação não pode, já em 1891, ser compreendida nos moldes clássicos da impressão sensorial como um elemento isolado, mas sim nos moldes de um modelo psicológico representacional que se desenvolve a partir de algo que exige uma noção de processo. Daí não se poder conceber a imagem mnêmica independentemente da associação, tanto no nível psicológico quanto no neurológico. Freud é, portanto, um associacionista, mas partidário de um associacionismo dinâmico que antevê um processo energético subjacente à manutenção das direções associativas. Essas associações são estruturadas na forma do esquema psicológico:

A palavra é, portanto, uma complexa representação que consiste nas imagens mencionadas ou, por outros termos, à palavra corresponde um intricado processo associativo em que vêm a entrar os elementos já mencionados, de proveniência visual, acústica e cinestésica. 
Mas a palavra adquire a sua denotação pela ligação com a 'representação objectual', pelo menos se nos limitarmos à consideração dos substantivos. Por outro lado, a representação objectual é por sua vez um complexo associativo das mais diversas representações visuais, acústicas, tácteis, cinestésicas.

Da filosofia aprendemos que a representação objectual não compreende senão isto, e que a aparência de uma 'coisa', de cujas diferentes 'propriedades' falam aquelas impressões sensoriais, surge apenas na medida em que no leque das impressões sensoriais obtidas por um objecto incluirmos também a possibilidade de uma longa sucessão de novas impressões na mesma cadeia associativa [ Mill, 1843/1979, conforme citado por Freud, 1891/1977, p. 70).

Em suma, a representação objectual aparece-nos como uma representação não fechada e dificilmente susceptível de fecho, ao passo que a representação de palavra nos aparece como algo de fechado embora susceptível de ampliação.

Este é o cerne da concepção freudiana de linguagem em sua relação com o pensamento. Além dessas frases só há a consideração anteriormente apresentada do símbolo como a associação entre a representação de palavra e a de objeto, se dando entre a imagem acústica da palavra e a associação visual do objeto.

Na verdade, Freud (1891/1977) não denomina explicitamente a natureza da relação que se estabelece entre a representação de palavra e a de objeto. É da afirmação da afasia simbólica que se depreende a natureza simbólica da relação entre as representações de palavra e de objeto. Da mesma forma, não se afirma, nesse texto freudiano, a natureza necessariamente arbitrária dessa ligação, mas sim o caráter mais superassociado dessa associação em relação às associações que constituem os complexos representacionais de palavra e de objeto. Essa afirmação permite que se derivem circunstâncias arbitrárias que motivem as associações superiores da linguagem, mas isso não está de forma alguma explicitado.

O primeiro ponto a se destacar é que o autor especifica claramente sua fonte da concepção associacionista: Stuart Mill, de quem o próprio Freud traduziu um livro para o alemão. Esse autor, como se sabe, foi um herdeiro do empirismo inglês, notadamente de Hume e de seu próprio pai, James Mill. Tal como o primeiro, aceitará a noção de que o sujeito não pode efetivamente conhecer o mundo, mas apenas construí-lo associativamente como crença. Do segundo, se diferencia pela elaboração da noção de química mental em oposição à física mental. Stuart Mill, como todo empirista, acredita na constituição do sujeito através da impressão deixada pelos objetos percebidos do mundo. Esses objetos se implantariam na consciência e se organizariam de forma coerente a partir de princípios associativos. Para Mill (1843/1979), o conjunto de elementos associados não poderia ser entendido de forma molecularista, pois a combinação de elementos daria a origem a um complexo que conteria mais do que as suas partes constituintes, daí a referência à química. Tem-se, portanto, um associacionismo de natureza molar, cuja cadeia crescente de vinculações é capaz de criar uma representação de mundo psicologicamente coerente, mas não necessariamente verdadeira desde o ponto de vista epistemológico (Garcia-Roza, 1998; Loffredo, 1999).

De acordo com Garcia-Roza (1998) e Loffredo (1999) a concepção do associacionismo nominalista de Mill (1843/1979) assenta-se sobre quatro teses, que culminam em uma visão particular de matéria e de mundo exterior, a qual se mostra oscilante entre o realismo e o idealismo. O primeiro ponto é o de que a mente humana é capaz de expectativa, ou seja, que sobre as percepções reais a mente forma a concepção de sensações possíveis. São justamente essas possibilidades de sensação que aparecem como um horizonte perceptivo previsto que fundam a crença no mundo exterior e na matéria. Isso implica dizer que o associacionismo de Mill (1843/1979) confere um papel dinâmico e ativo aos complexos associativos, os quais são responsáveis pela orientação da consciência frente aos objetos que o mundo revela. A percepção nunca ocorre de forma isolada ou pura, mas sempre no contexto de um movimento associativo da consciência e, além disso, é sempre hipotética, pois se dá em função dessa expectativa criada. As possibilidades de sensação consolidadas na mente nada mais são do que a idéia de matéria, ou seja, não uma substância isolada e independente da consciência, mas uma trama associativa coerente que reflete a coisa em si na consciência. Esse status de coerência faz com que a trama de representações seja a própria "substância" mental. Freud (ano?), portanto, recorre a Stuart Mill para afirmar a impossibilidade de acesso ao objeto em si, de tal forma que é apenas a cadeia associativa que constitui a representação de objeto.

É preciso, ainda, entender como a matéria se constitui. Entra aí a segunda tese: as leis de associações de idéias. Stuart Mill (1843/1979) afirma quatro princípios: semelhança, contiguidade, frequência e inseparabilidade. A idéia é que as associações produzidas por contiguidade tornam-se mais exatas e acessíveis pela repetição. Ou seja, a frequência associativa aumenta o grau de certeza. A ação desse princípio, por sua vez, leva à constituição de associações inseparáveis. Nesse ponto, o vínculo entre as representações é tão firmemente fixado que as próprias coisas passam a ser concebidas como existindo conjuntamente. Funda-se, assim, a crença da coexistência das coisas, a qual, apesar de ser um produto da experiência, aparece como uma intuição dos objetos do mundo exterior. Percebe-se que Stuart Mill (1979), tal como Hume, elimina tanto a noção de uma substância material como a de uma substância espiritual. A matéria nada mais é do que o resultado de uma associação inseparável; a sucessão de uma possibilidade permanente de sensações. Trata-se, portanto, de uma rede associativa tanto dos estados objetivos quanto dos estados subjetivos, a qual se articula como crença. 
Encontramo-nos diante do mais puro ceticismo empirista. Stuart Mill (1979) descarta o acesso da consciência a um objeto exterior. A partir desses elementos, podemos interpretar que Freud (1891/1977) também parta dessa posição epistemológica. Isso não quer dizer, contudo, que a consciência não seja constituída por intermédio da relação com o mundo externo. Ter eliminado a equivalência entre a coisa em si e a representação de objeto, não implica a exclusão completa da referência do campo de investigação da psicologia e, no caso de Freud, da incipiente psicanálise. Ao se apoiar em Stuart Mill, o autor se alinha à tendência moderna de colocar em questão a relação entre o objeto e o psiquismo, mas isso não implica, necessariamente, uma congruência com as tendências das ciências da linguagem contemporâneas de excluir completamente o referente. Permanece a referência ao objeto externo mediada por meio do teste de realidade, que será um elemento regulador fundamental dos princípios de funcionamento mental.

Uma questão que o esquema freudiano levanta é o estatuto do outro humano na constituição do aparelho de linguagem. A pergunta parece ingênua, uma vez que uma competência linguística só poderá se estruturar na relação mediada com outro aparelho de linguagem, já que a língua é um código intersubjetivo. Contudo, há de se perguntar se o tratamento dado por Freud aos efeitos de sentido do outro sobre a constituição psíquica parte de uma concepção epistemológica em que o outro tenha um papel determinante na constituição do sujeito e não seja um mero objeto a ser representado por uma consciência solipsista. Se tomarmos como referência o empirismo explícito de Freud (1891/1977) nesse texto e o conjunto das doutrinas epistemológicas que o sustenta pode-se afirmar que esse tipo de concepção do outro não está presente. Contudo, também é possível afirmar que, desde o início, Freud está preocupado com a constituição do psiquismo por meio da relação com o outro (Garcia-Roza, 1998; Loffredo, 1999). O problema é saber em que bases filosóficas essa relação intersubjetiva é trabalhada. Portanto, a teoria freudiana se depara com o seguinte problema epistemológico: saber como se constitui a relação intersubjetiva, o que envolve definir se ela se dá sob o ponto de vista estrito da linguagem ou comportando outras formas de doação de sentido e, além disso, se é possível incluir o outro na própria constituição e na origem da subjetividade. Esse é um ponto crucial na compreensão da teoria da representação freudiana cuja incursão pela filosofia da linguagem, presente na monografia em questão, permite discutir.

\section{Duas interpretações do esquema freudiano}

A partir da exposição do associacionismo nominalista de Stuart Mill (1843/1979) como concepção inspiradora da teoria freudiana sobre a linguagem, pode-se agora retornar à elucidação do esquema psicológico e contrapô-lo ao ponto de vista de alguns comentadores que defendem aí uma concepção seminal da obra freudiana. Veremos como essas interpretações divergem significativamente, sendo ilustrativas de duas formas de abordagem do problema da linguagem em sua relação com a teoria da representação freudiana.

Tanto Gabbi Jr. (1991) quanto Garcia-Roza (1998) comentam a ruptura de Freud com as concepções anatômicas em direção a uma dimensão semiótica e, mais precisamente, ao campo da linguagem. O primeiro afirma que a imagem acústica irá tomar o lugar de princípio heurístico, operando a troca da anatomia pela linguagem como universal para sua teoria sobre a histeria (Gabbi Jr., 1991). Já o segundo defende a hipótese de que a linguagem esteja "presente desde o começo", afirmando uma teoria da percepção original em Freud, na qual a linguagem comparece como fator determinante e originário da subjetividade (GarciaRoza, 1998).

Sabe-se, como acentuou Birman (1991), que a constituição da psicanálise como campo autônomo de saber é função da passagem de um corpo anátomo-fisiológico para o corpo representado. Assim, a experiência psicanalítica se funda em um deslocamento de natureza simbólica. A questão é entender como se organiza essa dimensão. Alguns enveredarão para uma concepção estritamente linguística da questão, outros não. Ainda que admitindo a abordagem pelo viés da linguagem, é preciso definir que linguagem está em jogo.

Retomando o esquema psicológico de Freud (1891/1977), observa-se que a relação entre a representação de palavra e a representação de objeto é simbólica. $\mathrm{O}$ símbolo, portanto, tem como referente às associações de objeto e não o objeto externo, o qual é incognoscível. Como foi visto, Freud afirma duas coisas sobre essa relação: (a) que nos substantivos o significado da representação de palavra é dado pela associação com a representação de objeto; (b) a representação de objeto, por sua vez, tem sua identidade dada pela longa trama associativa das expectativas de objeto. Parece claro que a concepção seja a seguinte: a crença no mundo, ou seja, a articulação das sensações em complexos associativos que constituem representações de objetos, se dá em um nível inicialmente perceptivo. A linguagem se desenvolve sobre o solo dessa crença. As representações de palavra adquirem seu significado denotativo a partir da ligação com as representações de objeto. Esse elo seria patente na denominação dos substantivos, que teriam um significado mais concreto, de modo que a linguagem se desenvolveria sobre os símbolos naturais. Freud, contudo, não expressa claramente a natureza dessa ligação. Se não é sempre simbólica, ou motivada, também não é exclusivamente sígnica, ou arbitrária. O que é certo é que a linguagem remete ao significado do objeto. A idéia é que o sintoma seja entendido como o termo de um processo de simbolização patológica:

um simbolo que substitui outra representação que não pode ter acesso à consciência e que se desfaz quando é esclarecido, isto é, quando é identificado a que ele se remete. Isso quer dizer que o que está 
no papel de causa é, simultaneamente, aquilo que na formação do símbolo é a sua referência (Loffredo, 1999, p. 180).

Como vimos, é a perda da relação entre a representação de objeto e a de palavra que caracteriza a afasia simbólica. Da mesma forma, é o deslocamento dessa ligação pela operação defensiva que cria o símbolo mnêmico. Isso permite a afirmação, defendida por Gabbi Jr. (1991), de que a afasia simbólica será tomada por Freud como modelo para pensar a formação do sintoma na histeria.

Vimos também que a colocação em suspenso do referente, operada por Stuart Mill (1843/1979) e retomada por Freud (1891/1977), não implica uma concepção de linguagem em que o problema do referente esteja resolvido. De qualquer forma, a referência aqui não diz respeito ao objeto externo de uma forma direta, mas sim ao campo das associações de objeto. Essa significação é pensada a partir dos símbolos naturais e com certa autonomia da representação de objeto em relação à representação de palavra.

Como aponta Loffredo (1999) Freud nunca deixará de perseguir a ligação original entre a representação de objeto e a representação de palavra. Essa busca pela referência dentro do campo das representações fará com que sua teorização futura procure sempre as origens da fantasia. Esse ponto de partida levou-o a se instrumentalizar de uma noção de verdade por correspondência, em vez de concebê-la como consistência interna.

A eleição da afasia simbólica como paradigma não é casual. Se, em vez da ligação entre a representação de objeto e a de palavra, Freud tomasse afasia verbal, isto é, a articulação entre as representações de palavra entre si sem levar em conta a representação de objeto, estaria partindo de outra concepção de linguagem ou mesmo de verdade. Nesse caso, estaria em jogo uma posição em que os processos de pensamento seriam tomados a partir do raciocínio contemporâneo, montado a partir do aporte das ciências da linguagem.

A interpretação da monografia freudiana a partir da filosofia de Stuart Mill, tal como defendida por autores como Gabbi Jr. (1991) e Loffredo (1999), é mais próxima ao contexto próprio de emergência dos conceitos psicanalíticos, revelando as dificuldades das referências freudianas para lidar com a própria originalidade da descoberta do inconsciente.

A leitura efetuada por Garcia-Roza (1998), por sua vez, é mais interpretativa e tendenciosa. Acredito que o viés se dá no sentido de extrapolar o argumento freudiano justamente para minimizar a precedência da representação de objeto e exaltar a prevalência da representação de palavra. A razão desse movimento parece não ser outra que a de marcar a primazia do significante já no primeiro texto teórico freudiano. Em outras palavras, trata-se de uma leitura sob as lentes de Lacan, o que envolverá um sutil deslocamento da noção de verdade por correspondência para a de consistência interna e de uma filosofia da linguagem que busca a significação na relação entre a palavra e o conceito para outra que compreende a significação no seio das relações extrínsecas aos elementos de um sistema de signos.

Alguns passos dessa interpretação precisam ser questionados. O primeiro ponto é a idéia de que Freud tenha afirmado a relação simbólica como necessariamente arbitrária, o que, como se viu, não pode ser sustentado. O segundo ponto parte dessa relação e envolve uma série de derivações que surgem de algo que não é expressamente trabalhado no texto de Freud (1891/1977) e que não pode ser sustentado a partir das concepções filosóficas por ele assumidas. $\mathrm{O}$ argumento é o seguinte:

A relação de significação não se faz com a coisa, mas com o objeto, e este recebe sua identidade através da relação com a representação-palavra. (...) Se é pela sua articulação com a representação-objeto que a representação-palavra adquire sua significação (ou sua denotação), é também pela sua articulação com a representação-palavra que o objeto ganha identidade e que é possível uma implicação de conceito. Como não há conceito sem significação, assim como não há significação sem palavra, não há pensamento anterior às palavras. A linguagem está presente desde o começo (Garcia-Roza, 1998, p. 49).

Freud não afirma que o objeto recebe sua significação pela relação com a representação de palavra, mas o contrário. É interessante notar como em tão poucas linhas a representação de palavra possa, de elemento derivado, passar a fator constituinte. A concepção de simultaneidade entre significante e significado na gênese dos signos é uma concepção estrutural que se opõe ao nominalismo do esquema freudiano. Assim, a concepção contemporânea é aplicada ostensivamente, transformando uma problemática em um fato evidente. A posição de que a representação de palavra, pelo menos primariamente, recebe a significação da representação de objeto é defendida, também, por Caropreso (2003).

A primeira extrapolação do argumento freudiano é afirmar que a relação de significação seja recíproca, ou seja, não só a palavra adquire a significação, mas o objeto ganha identidade e conceituação. Aqui estão em jogo níveis diferentes de abordagem: uma coisa é dizer que um complexo associativo é formado e unificado na forma de uma associação inseparável, ou seja, uma unidade material indivisa; outra é dizer que um complexo associativo ganha a implicação de conceito. O que Freud (1891/1977) diz a respeito do objeto é bastante claro: a identidade da representação de objeto é dada pelas múltiplas associações possíveis, daí o seu caráter de complexo associativo aberto. Isso quer dizer que não é uma contingência a representação de objeto ser um complexo associativo aberto, mas sua própria identidade decorre da trama das expectativas. O objeto, portanto, não precisa da linguagem para se constituir enquanto crença. Ele é dado pela própria síntese perceptiva, sendo construído pelas impressões do mundo exterior enquanto representação. Assim, 
a representação de objeto não é de caráter linguístico, ou criada pela linguagem. Outra coisa é dizer que a representação de objeto ganhe a implicação de conceito, ou seja, que os objetos sejam reunidos enquanto categorias e relacionados a um símbolo que os denote. De fato, o símbolo ou signo não pode ser entendido a não ser na relação semiótica, daí decorre que a implicação de conceito só poderá ser entendida na relação com a representação de palavra.

Pode-se, portanto, concordar com Garcia-Roza (1998) a respeito da implicação de conceito, mas não da identidade. O interessante é que o próprio autor levará isso em consideração no seguimento do texto sem, no entanto, notar a indistinção que opera entre identidade e conceito; entre o que é da ordem da experiência pré-reflexiva e o que é da ordem da consciência reflexiva:

No entanto, não parece ser essa a intenção de Freud [conceber a representação de objeto como um ícone da coisa]. Para ele, embora a representação-objeto não pertença ao aparelho de linguagem, ela só se constitui como um complexo associativo, adquirindo sua identidade, pela sua ligação com a representação-palavra. O conceito não se faz senão na e pela linguagem (Garcia-Roza, 1998, p. 63).

Observa-se que o autor, apesar de admitir aquilo que se mostrou tão caro a Freud, deixa-o progressivamente em segundo plano. O resultado do raciocínio é o seguinte: as representações de objeto são conceitos criados exclusivamente pela linguagem. O silogismo é bastante simples: (a) não há conceito sem significação; (b) não há significação sem palavras; logo (c) não há conceitos sem palavras.

O problema é atestar a validade absoluta dessas premissas. É necessário, portanto, definir significação. Garcia-Roza (1998) tende a afirmar que o signo é uma relação icônica, ou seja, a representação é motivada pelo objeto. Já o símbolo seria a relação propriamente linguística, de natureza arbitrária. Insiste em colocar o primeiro na relação da coisa em si com a representação de objeto e o segundo na relação da representação de objeto com a palavra. Como a representação de objeto não reproduz o objeto em si, Garcia-Roza (1998) acredita que a significação só poderá ser entendida a partir da relação simbólica, excluindo toda a significação motivada ou natural de jogo e, consequentemente, toda a posição empirista cética presente em Freud. A partir dessa redução do campo da semiótica, fica fácil considerar que não haja pensamento sem linguagem e, de forma ainda mais tendenciosa, que a linguagem funde o pensamento.

Esse é o percurso do raciocínio que insere, no esquema psicológico freudiano, a primazia da linguagem. Acredito que pude demonstrar como essa derivação não pode ser efetuada com os elementos trazidos pelo texto freudiano. Afinal, o que está em jogo é uma teorização sobre as relações entre linguagem e pensamento que não parece estar resolvida por Freud em 1891 e não o será em toda a sua obra. O ponto de chegada de Garcia-Roza (1998) não é outro senão preparar o terreno para uma concepção linguística que elimina não só o referente externo, mas, também, a referência em relação à representação de objeto. Assim, a idéia lacaniana de uma autonomia do significante, que diz respeito à necessidade de tematização da problemática da enunciação dentro da estrutura linguística, é utilizada para justificar a exclusão do significado do campo epistemológico da psicanálise.

Opera-se, por meio da negação da concepção referencial de Freud, a destruição definitiva da linha entre representação de objeto e representação de palavra. Nesse caso, em vez de se tomar o ponto de ancoragem freudiano em uma teoria da representação mental, toma-se o partido de uma abordagem contemporânea baseada nas ciências da linguagem.

Mesmo concordando que uma concepção referencial e uma noção de verdade por correspondência trarão problemas para a teoria freudiana, não se pode acatar uma interpretação que procura eliminá-la logo na origem, subvertendo a filiação teórica da qual Freud parte. Sabe-se que a interpretação da psicanálise pelas abordagens linguísticas contemporâneas é responsável pela superação do modelo representacional na metapsicologia, já que é contra os resíduos mentalistas e representacionais da metapsicologia que essas abordagens se posicionam, colocando em novas bases os temas que Freud elaborou a partir de uma teoria psicológica do século XIX. Não estou, com isso, afirmando que essas interpretações sejam equivocadas ou defendendo um "purismo" freudiano, o que seria uma ortodoxia. Inserir a metapsicologia freudiana diretamente em uma problemática contemporânea, porém, é cometer um erro de ilusão retrospectiva.

Nesse sentido, é notável a forma com a qual a filosofia de Stuart Mill é escamoteada sistematicamente por GarciaRoza (1998). O argumento é que a concepção de Stuart Mill não é suficiente para explicar a relação entre representação de objeto e a representação de palavra, sendo esclarecedora apenas no que diz respeito ao caráter aberto da representação de objeto. Realmente, o associacionismo nominalista não dará papel de destaque à linguagem, sendo sua principal preocupação a constituição empírica da matéria através das expectativas. Isso não é pouco, pois afirma a experiência em geral como fundadora da subjetividade e da consciência, não a linguagem. O problema é que Stuart Mill não trata a linguagem como exclusiva doadora de sentido. De fato, o lugar genético da linguagem não se mostra claro em Stuart Mill, o mesmo ocorrendo no texto de Freud (1891/1977).

A partir da crítica à leitura de Garcia-Roza (1998) da monografia de Freud, pode-se afirmar que sua concepção de linguagem como universal se afasta radicalmente da posição aqui defendida. Naquele caso, a linguagem não aparece como fundamento de um método de investigação, mas como fundamento ontológico. As críticas acima mostram como essa posição é discutível e, além disso, que ela não pode ser derivada das posições de Freud (1891/1977) no texto das afasias.

\section{Considerações finais}

A discussão precedente teve a finalidade de analisar algumas interpretações do estudo sobre as afasias, com o intuito de discutir as contribuições desse texto inaugural no 
que diz respeito à definição da linguagem em sua relação com o pensamento e a realidade. Esse assunto, por sua vez, nos permitiu discorrer sobre o tema mais geral do lugar do simbólico na teoria freudiana e, mais especificamente, sobre a incidência e os reflexos das concepções sobre a linguagem na teoria da representação psíquica.

Quanto à abordagem das representações em sua relação com o somático, foi visto que a monografia sobre as afasias traz uma defesa importante do paralelismo psicofisiológico. Essa posição, ainda incipiente, deverá aguardar alguns desdobramentos importantes para seu arremate sob o conceito de pulsão. O interessante é notar o duplo encaminhamento desse problema, que será abordado em nível neuronal e em nível representacional nos textos metapsicológicos posteriores.

Outro ponto importante é a problematização da patologia entendida como perturbação funcional. Essa funcionalidade remete a uma concepção extremamente original das relações entre representação e associação. Entra em cena o esboço de um investimento energético que organize a malha de traços e representações, por meio de uma hierarquização de níveis associativos. Decorre daí a proposta de um esquema psicológico que vincule representações de objeto e de palavra associadas por intermédio da imagem acústica da palavra e da imagem visual do objeto.

Uma incursão pelo problema do símbolo na psicanálise mostrou que a articulação entre essa concepção e aquela que será desenvolvida pelas ciências da linguagem não se dá de forma imediata, precisando de uma série de intermediações para que os efeitos de sentido próprios à experiência psicanalítica sejam equacionados ao campo das teorias sobre a linguagem. Essas intermediações implicam tanto a desvinculação da teoria psicanalítica de seus resquícios mentalistas e representacionais quanto à passagem de uma abordagem estrutural da linguagem para sua dimensão pragmática. Ou seja, o problema dos efeitos de sentido é comum aos dois campos e é nos seus desdobramentos que o símbolo da psicanálise encontra o da linguística. Contudo, o problema do símbolo se mostra secundário na teoria freudiana, uma vez que o foco está voltado para a motivação inconsciente e individual dos sintomas, e, além disso, a simbolização compreende outras dimensões, de caráter energético e afetivo que serão mais importantes para a investigação freudiana.

Saindo das linhas gerais do problema e adentrando nos conceitos de representação de objeto e de palavra, pôde-se discutir questões fundamentais da tríade semiótica: a relação entre o referente externo, a idéia e a palavra. O ponto mais claro é a relação das representações com a realidade externa. O autor afirmará a impossibilidade de acesso ao objeto em si sem, contudo, cair em um idealismo. Pode-se inferir daí uma filosofia da linguagem inspirada no associacionismo nominalista. Contudo, não está clara a relação entre o nível objetal e o verbal das representações, da mesma forma em que não é clara a sua vinculação com a concepção de símbolo. Mostrou-se, entretanto, que algumas interpretações não encontram apoio no texto freudiano, como a de que a linguagem funda a consciência, nem a de que o símbolo seja exclusivamente arbitrário, tampouco a de que as relações entre a representação de palavra e a de objeto sejam de prevalência e precedência da primeira sobre a segunda, colocando a teoria representacional freudiana em vinculação direta com uma teoria linguística estrutural. Portanto, não se pode vincular diretamente o esquema psicológico das afasias com a noção saussuriana de signo, muito menos com os desdobramentos posteriores das ciências da linguagem. Em suma, a linguagem em Freud restringe-se a uma abordagem psicológica e não linguística.

Uma abordagem da representação sob o prisma da linguagem é um passo necessário, porém insuficiente para o estudo da teoria representacional freudiana. Ela precisa ser complementada pelas outras facetas da representação na metapsicologia, notadamente a vinculação da representação ao processo defensivo e seu enraizamento em uma concepção de natureza energética do afeto. Por fim, essa teoria da representação precisa ser articulada a um modelo geral do funcionamento mental, ou seja, é preciso tematizar a dinâmica representacional constituinte de um aparelho psíquico. Esses serão os passos posteriores de Freud em sua jornada rumo à constituição do objeto da psicanálise: o inconsciente.

\section{Referências}

Arrivé, M. (1994). Linguística e psicanálise: Freud, Saussure, Hjelmslev, Lacan e outros (L. Magalhães, Trad.). São Paulo: EDUSP. (Original publicado em 1986)

Auroux, S. (1998). A Filosofia da linguagem (J. H. Nunes, Trad.). Campinas: UNICAMP. (Original publicado em 1996)

Birman, J. (1991). Freud e a interpretação psicanalítica: A constituição da psicanálise. Rio de Janeiro: RelumeDumará.

Caropreso, F. (2003). O conceito freudiano de representação em 'sobre a concepção das afasias'. Paidéia (Ribeirão Preto), 13, 13-26.

Freud, S. (1977). A interpretação das afasias (A. P. Ribeiro, Trad.). Lisboa: Edições 70. (Original publicado em 1891)

Freud, S. (1995). Projeto de uma psicologia (O. F. Gabbi Junior Trad). Rio de Janeiro: Imago. (Original publicado em 1895)

Freud, S. (1996). A interpretação de sonhos. In S. Freud, Edição standard brasileira das obras psicológicas completas de Sigmund Freud (Vols. 4-5) (J. Salomão, Trad.). Rio de Janeiro: Imago. (Original publicado em 1900)

Freud, S. (1996). As neuropsicoses de defesa. In S. Freud, Edição standard brasileira das obras psicológicas completas de Sigmund Freud (Vol. 3, p. 51-74) (J. Salomão, Trad.). Rio de Janeiro: Imago. (Original publicado em 1894) 
Gabbi Jr., O. F. (1991). Sobre a concepção da afasia e da histeria: Notas sobre a relação entre anatomia e linguagem nos primórdios da teoria freudiana. In B. Prado Jr. (Org.), Filosofia da psicanálise (pp. 181-198). São Paulo: Brasiliense.

Garcia-Roza, L. A. (1998). Introdução à metapsicologia freudiana 1 (4a ed). Rio de Janeiro: Jorge Zahar.

Laplanche, J., \& Pontalis, J. B. (1998). Vocabulário da psicanálise (P. Tamen, Trad., 3a ed.). São Paulo: Martins Fontes. (Original publicado em 1987)

Loffredo, A. M. (1999). Em busca do referente, às voltas com a polissemia dos sonhos: A questão em Freud, Stuart Mill e Lacan. Psicologia USP, 10(1), 169-197.

Mill, J. S. (1979). Sistema de lógica indutiva e dedutiva e outros textos (J. M. Coelho \& P. R. Mariconda, Trads., 2a ed., pp. 81-255, Coleção os Pensadores). São Paulo: Nova Cultural. (Original publicado em 1843)

Oliveira, M. A. (1996). Reviravolta lingüístico-pragmática na filosofia contemporânea. São Paulo: Loyola.

Winograd, M. (2004a). Entre o corpo e o psiquismo: A noção de concomitância dependente em Freud. Psychê, 8(14), 95-108.

Winograd, M. (2004b). Freud é monista, dualista ou pluralista? Ágora, 7, 203-220.

Érico Bruno Viana Campos é Professor Adjunto do Centro Universitário Hermínio Ometto de Araras (UNIARARAS) e mestre em Psicologia pelo Programa de Pós-graduação em Psicologia Experimental do Instituto de Psicologia da Universidade São Paulo.

Recebido: 18/05/2008

$1^{a}$ revisão: 16/02/2009

$2^{a}$ revisão: $13 / 04 / 2009$

$3^{a}$ revisão: 24/07/2009

Aceite final: 18/08/2009 